\title{
Inhibition of histone deacetylase (HDAC) by 4-phenylbutyrate results in increased junctional conductance between rat corpora smooth muscle cells
}

\section{Hong Zhan Wang ${ }^{1}$, Barbara Rosati ${ }^{1,2}$, Chris Gordon ${ }^{1}$, Virginijus Valiunas ${ }^{1,2}$, David McKinnon ${ }^{2,3}$, Ira S. Cohen ${ }^{1,2}$ and Peter R. Brink ${ }^{1,2 *}$}

\author{
${ }^{1}$ Department of Physiology and Biophysics, Stony Brook University, Stony Brook, NY, USA \\ ${ }^{2}$ Department of Physiology and Biophysics, Molecular Cardiology Institute, Stony Brook University, Stony Brook, NY, USA \\ ${ }^{3}$ Department of Neurobiology and Behavior, Stony Brook University, Stony Brook, NY, USA
}

\section{Edited by:}

Trinity Jude Bivalacqua, Johns

Hopkins Hospital, USA

Reviewed by:

Martin C. Michel, Boehringer

Ingelheim GmbH, Germany

Graça Almeida-Porada, Institute for

Regenerative Medicine, USA

*Correspondence:

Peter R. Brink, Department of Physiology and Biophysics, School of Medicine, Stony Brook University, Stony Brook, NY 11733, USA

e-mail: peter.brink@stonybrook.edu 4-phenylbutyrate (4-PB) has been shown to increase the protein content in a number of cells types. One such protein is Connexin43 (Cx43). We show here that 4-phenylbutyrate exposure results in significantly elevated cell to cell coupling, as determined by dual whole cell patch clamp. Incubation with $5 \mathrm{mM} 4 \mathrm{~PB}$ for $24 \mathrm{~h}$ or more nearly doubles junctional conductance. Interestingly, mRNA levels for Cx43 declined with exposure to 4-PB while western blot analysis revealed not significant change in protein levels. These data are most consistent with stabilization of the existing $\mathrm{C} \times 43$ pool or alterations in the number of functional channels within an existing pool of active and silent channels. These data represent a baseline for testing the efficacy of increased connexin mediated coupling in a variety of multicellular functions including erectile function.

Keywords: 4-phenylbutyrate, connexin43, cell to cell coupling, patch clamp, protein expression

\section{INTRODUCTION}

Corpora Cavernosa smooth muscle cells form a functional syncytium as a consequence of connexin derived gap junction channels connecting cell interiors (Harris, 2001). The most ubiquitously expressed connexin gene in corpora smooth muscle is Connexin43 (Cx43) (Asklund et al., 2004). Reduced expression of connexins has been implicated as a major contributor to impaired function with reduced expression of connexins (Melman and Christ, 2001). Further, a number of studies strongly suggest that $\mathrm{Cx} 43$ expression and gap junction mediated coupling are essential for relaxation of corpora smooth muscle cells and hence erectile response (Christ and Lue, 2004; Pointis, 2006; Fu et al., 2008; Suadicani et al., 2009).

A relevant question becomes: can up-regulation or enhanced functionality of $\mathrm{Cx} 43$ lessen erectile dysfunction? To assess this possibility it is first necessary to assess Cx43 expression and junctional conductance in corpora smooth muscle cell pairs.

Up-regulation of connexin expression can be accomplished with exposure to mild hyperthermia (VanSlyke and Musil, 2005). The expression of adhesion molecules such as alpha and beta catenin and cadherin can also affect connexin expression (Jongen et al., 1991; Prowse et al., 1997; Wei et al., 2005) and organ function (Ferreira-Cornwell et al., 2002; Li et al., 2006). The antiarrhythmic peptide ZP123 (Rotigaptide) has also been to shown to increase junctional conductance in cardiac myocyte pairs as much as 69\% within minutes (Eloff et al., 2003; Xing et al., 2003; Axelsen et al., 2006) but it has not been shown to affect expression levels suggesting that it acts to recruit channels from a silent pool. The idea of a silent reservoir is based on the fact that active $\mathrm{Cx} 43$ channels in corpora have been shown to have open probabilities approaching between 0.5 and unity (Brink et al., 1996; Christ and Brink, 1999).

Another choice is chemical stimulation with 4-PB (Asklund et al., 2004) that inhibits histone deacetylases (HDACs), enzymes associated with inactivation of gene transcription (Perlmutter, 2002; Asklund et al., 2004; Iwasaki et al., 2006). 4-PB is an FDA approved drug that can be administered orally and is currently being tested for effectiveness in spinal muscular atrophy (Wirth et al., 2006), cystic fibrosis (Singh et al., 2006), and cancer (Tang et al., 2004). In vitro studies on cancer cell lines are of particular interest as they suggest $\mathrm{Cx} 43$ up-regulation results in channel recruitment. Asklund et al. (2004) found that $5 \mathrm{mM} 4-\mathrm{PB}$ increased Cx43 expression two- to five-fold with exposure times of hours to days in human glioblastoma cells and also reduced proliferation rate two- to three-fold and Khan et al. (2007) found that 4-PB induced apoptosis in human glioma cells. 4-PB has also been shown to elevate $\mathrm{Cx} 43$ expression in both $\mathrm{Cx} 43$ transfected cells (HeLa) and cells that endogenously express Cx43 (HEK-293) (Kaufman et al., 2013). All three studies also noted that exposure to 4-PB enhanced fluorescent dye transfer between cells consistent with an increase in the number of functional gap junction channels linking cell interiors.

We have used dual whole cell patch clamp to monitor junctional conductance in rat corpora cavernosa cell pairs to determine if $4 \mathrm{~PB}$ exposure caused junctional conductance to increase between corpora smooth muscle cell pairs. We also 
monitored 4-PB effects on $\mathrm{Cx} 43$ expression using real-time PCR and Western Blot. We observed no significant change $\mathrm{Cx} 43$ protein levels contrary to previous reports (Asklund et al., 2004; Khan et al., 2007; Kaufman et al., 2013) but found that junctional conductance increased 1.4-fold after $24 \mathrm{~h}$ of exposure and attained a maximum increase of 1.8 -fold after $72 \mathrm{~h}$ of exposure to $4 \mathrm{~PB}$. Voltage dependence was not affected by $4 \mathrm{~PB}$.

\section{METHODS \\ CELL SOURCE}

Rat corporal tissue was dissected from the rat penis as previously described (Rehman et al., 1997; Wang et al., 2001). Explant cultures of rat corporeal cells were prepared as follows. Short-term cultures, i.e., passages 0-2, were prepared from freshly isolated rat corporeal myocytes (Wang et al., 2001) Cells were plated on $35 \mathrm{~mm}$ dishes and allowed to attach and proliferate for 1-2 days (passage 0 ) or they were split upon confluence (passage 1) prior to trypsinization and resuspension onto cover dishes for patch clamp analysis (Rehman et al., 1997; Wang et al., 2001).

\section{PATCH CLAMP}

Dual whole cell patch clamp of cell pairs was used as previously described (Wang et al., 2001; Valiunas et al., 2002). Media was exchanged for a buffered solution containing $150 \mathrm{mM} \mathrm{NaCl}$, $4 \mathrm{mM} \mathrm{KCl}, 1 \mathrm{mM} \mathrm{MgCl} 2,5 \mathrm{mM}$ HEPES, $2 \mathrm{mM}$ pyruvate, and $2 \mathrm{mM} \mathrm{CaCl}_{2}$, pH 7.2 containing no 4-PB. The pipette solution contained $130 \mathrm{mM} \mathrm{KCl}, 10 \mathrm{mM} \mathrm{NaCl}, 1 \mathrm{mM} \mathrm{MgCl}_{2}, 10 \mathrm{mM}$ egtazic acid and $1 \mathrm{mM} \mathrm{CaCl}_{2}, \mathrm{pH}$ 7.0. Pipette resistance varied from 2 to $5 \mathrm{M} \Omega$. Step protocols to monitor junctional conductance were as previously described (Wang et al., 2001). Data analysis was performed as previously described to determine voltage dependence, and junctional conductance (Valiunas et al., 2001; Wang et al., 2010).

\section{WESTERN BLOT}

Rat corpora smooth muscle cells or rat mesenchymal stem cells were exposed to $4-\mathrm{PB}$ at concentrations of 0 , 1 , or $5 \mathrm{mM}$ for $48 \mathrm{~h}$. Cells were collected from cultures by first washing then scraping in cold PBS. Cell suspensions were centrifuged at $14,000 \mathrm{rpm}$ at $4^{\circ} \mathrm{C}$ for $10 \mathrm{~min}$ then the supernatants were removed. The pellets were resuspended in cold RIPA (RadioImmnuoprecipitation Assay) buffer (R0278, Sigma), protease inhibitor cocktail (AEBSF, Aprotinin, Bestatin hydrochloride, E64, EDTA, Leupeptin) (P2714, Sigma), sodium orthovanadate (S-6508, Sigma) and PMSF (P-7626, Sigma). Samples were kept on wet ice during the lysis step for $\sim 30 \mathrm{~min}$ and frequently vortexed. Samples were then centrifuged in an Eppendorf microfuge at $4^{\circ} \mathrm{C}, 14,000 \mathrm{rpm}$ for $10 \mathrm{~min}$, supernatants were transferred to new pre-chilled microtubes. Protein concentration of the samples was determined by the Bradford assay. Volumes containing $30 \mu \mathrm{g}$ of total protein for each dose point were mixed with equal volumes of Laemmli sample buffer (161-0737, Bio Rad) containing $\beta$-mercaptoethanol and boiled for $5 \mathrm{~min}$ at $95^{\circ} \mathrm{C}$. All samples were cooled then centrifuged briefly before being loaded on a SDS-polacrylamide gel (4\% stacking gel, 10\% separating gel). After separation by electrophoresis at $115 \mathrm{~V}$ for $90 \mathrm{~min}$ in trisglycine/SDS buffer, proteins were transferred to Immobilon-P membrane (Millipore) by electrophoresis at $100 \mathrm{~V}$ for $60 \mathrm{~min}$ in tris-glycine/methanol buffer. Non-specific antibody binding was blocked for $1 \mathrm{~h}$ at RT in 5\% Blotting Grade Blocker non-fat dry milk (Bio Rad) dissolved in 1x TBST. The membrane was washed briefly in 1x TBST (Wang et al., 2010).

For Cx43: a $43 \mathrm{kDa}$ protein was probed for by incubating the membrane with the anti-connexin 43 antibody (C 6219, Sigma) at 1:8000 in $1 \%$ milk for $1 \mathrm{~h}$ at room temperature. After washing the membrane well with $1 \mathrm{x}$ TBST the membrane was incubated for $1 \mathrm{~h}$ at room temperature with goat anti-rabbit IgG-HRP (sc-2004, Santa Cruz) at 1:10,000 in 1\% milk. After washing the membrane well with $1 x$ TBST the secondary antibody was detected using SuperSignal West Femto Maximum Sensitivity Substrate (34095, Pierce) and images obtained by exposing the membrane to HyBlot CL Autoradiography Film (E3012, Denville Scientific).

For Tubulin a $55 \mathrm{kDa}$ protein was probed for by incubating the membrane for $1 \mathrm{~h}$ at room temperature with Anti- $\alpha$-Tubulin (sc-8035, Santa Cruz) at 1:1000 in 1\% milk. After washing the membrane well with $1 x$ TBST the membrane was incubated for $1 \mathrm{~h}$ at room temperature with goat anti-mouse IgG-HRP (1858413, Pierce) at $1: 10,000$ in $1 \%$ milk. After washing the membrane well with 1x TBST the secondary antibody was detected using SuperSignal West Femto Maximum Sensitivity Substrate (34095, Pierce) and images obtained by exposing the membrane to HyBlot CL Autoradiography Film.

The Western blot results were evaluated by making comparisons between bands in different lanes. Quantification of the intensity of the protein bands seen on the X-ray film was done using the free NIH ImageJ software. First a digital image of the film was made with a scanner then converted to gray scale. A rectangular box was drawn around the first band and selected, the box was then moved to each of the other bands and again selected. Once all were selected the bands were then plotted which generated a graphical depiction of band intensities. Using the draw line tool each band histogram was marked off at its base. The magic wand tool was clicked inside each histogram, after each peak was selected, label peaks was clicked which generated numerical values of band intensities. The same procedure was done for the loading control and the experimental data was normalized resulting in adjusted density values.

\section{RNA EXTRACTION AND REAL-TIME PCR}

Total RNA was extracted from control and 4-PB treated corpora smooth muscle cell cultures (RNeasy Miniprep Kit, Qiagen, Valencia, CA). Three independent 100-mm diameter culture dishes were used for each experimental condition. The RNA samples were quantitated by optical density measurement and then diluted to the same nominal concentration. A second round of optical density measurement was performed to confirm the accuracy of this step. Five milligrams of RNA was used for cDNA synthesis (Superscript III reverse transcriptase, Life Technologies). The cDNA samples were diluted 1:16 prior to real-time PCR analysis.

Real-time PCR was performed with a StepOne Plus instrument (Life Technologies) using the QuantiFast SyBr Green PCR chemistry (Qiagen), as described previously (Rosati et al., 2011). The reaction mixture for each sample included the SyBr Green mastermix, $8 \mu \mathrm{L}$ of cDNA and $1.25 \mathrm{mM}$ of each gene-specific 
primer. The fast PCR amplification included a 5 min activating step at $95^{\circ} \mathrm{C}$, and 40 cycles of denaturation $\left(95^{\circ} \mathrm{C}\right.$ for $\left.10 \mathrm{~s}\right)$ and annealing-extension $\left(60^{\circ} \mathrm{C}\right.$ for $\left.27 \mathrm{~s}\right)$. Expression values were extracted automatically from the raw fluorescence data using a custom analysis program (Python/PyQt) with a standard threshold crossing algorithm (Ruijter et al., 2013). Multiple different primer pairs were prescreened and only combinations with similar amplification efficiencies were used in the experiments. The $18 \mathrm{~S}$ and 28S RNAs were used as internal controls, since expression of these did not vary significantly between the samples. Gene expression values were normalized to the average of the $18 \mathrm{~S}$ and $28 \mathrm{~S}$ expression values in each sample and expressed as relative values. Connexin 43 and internal control gene expression was analyzed using two gene-specific primer pairs per gene. The expression values obtained with each of the two pairs of primers were very similar and were averaged to obtain the final gene expression values.

The $5^{\prime}-3^{\prime}$ gene-specific primer sequences were:

$\begin{array}{ll}\text { Cx43(1) fwd: CGCCGGCTTCACTTTCATTA, } & \text { rev } \\ \text { TTGTCCAGAAGCTTCCCCAA } & \\ \text { Cx43(2) fwd: AGACTGCTTCCTCTCACGTC, } & \text { rev } \\ \text { AAAGCGAGAGACACCAAGGA } & \\ \text { 18S }(1) \quad \text { fwd: CTCAGCGTGTGCCTACCCTA, } & \text { rev } \\ \text { GACCCGCACTTACTGGGAT } & \\ \text { 18S }(2) \quad \text { fwd: CGGAACTGAGGCCATGATTA, rev } \\ \text { CTTTCGCTCTGGTCCGTCTT }\end{array}$

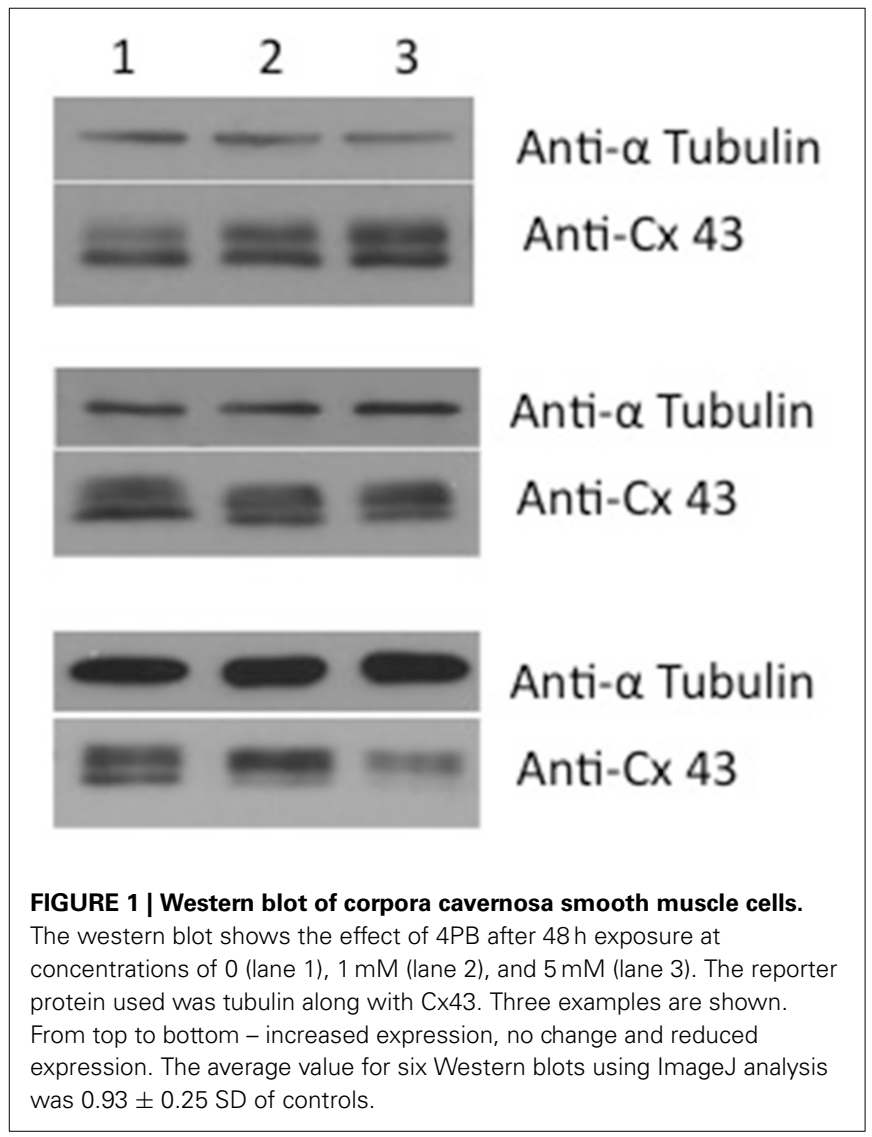

28S(1) fwd: CTCCGAAGTTTCCCTCAGGA, rev: GGCCCCAAGACCTCTAATCA

28S(2) fwd: AGGACCCGAAAGATGGTGAA, rev: TCGCCCCTATACCCAGGTC

Primers were designed using the Primer3 software (MIT: http:// primer3.ut.ee). All primer pairs were validated by electrophoresis analysis of the amplicons and the amplicons were sequenced to verify gene specificity.

\section{RESULTS}

Western blot analysis showed that exposure to 4-PB resulted in no change in $\mathrm{Cx} 43$ protein levels in rat corpora smooth muscle cells. Image analysis was performed on six western blots where controls (no 4PB) were compared to $4 \mathrm{~PB}$ expose preparations. Exposure time to $4 \mathrm{~PB}$ was $48 \mathrm{~h}$ yielding an average value of 0.93 \pm 0.25 (SD) for $4 \mathrm{~PB}$ exposed cells expressing $\mathrm{Cx} 43$. Figure 1 compares $\mathrm{Cx} 43$ protein levels along with a reporter gene, tubulin from three experiments illustrating the variability of $\mathrm{Cx} 43$ expression. In total six Western blot experiments were done and in each case normalized against a control (no 4-PB). 4-PB is not a specific enhancer of expression but rather a general tool able to modify the expression of some but not all proteins within a cell. Neither Cx43 nor tubulin expression was demonstrably affected by $4 \mathrm{~PB}$. In other cell systems increases of $\mathrm{Cx} 43$ have been reported (Asklund et al., 2004; Kaufman et al., 2013). Transcription level for $\mathrm{Cx} 43$ was also determined. We quantified Cx43 mRNA expression in control and 4-PB treated cells 24 and $48 \mathrm{~h}$ after addition of the drug/vehicle (Figure 2). There was a 56\% increase in Cx43 mRNA expression in the control corpora cells at $48 \mathrm{~h}$ compared to

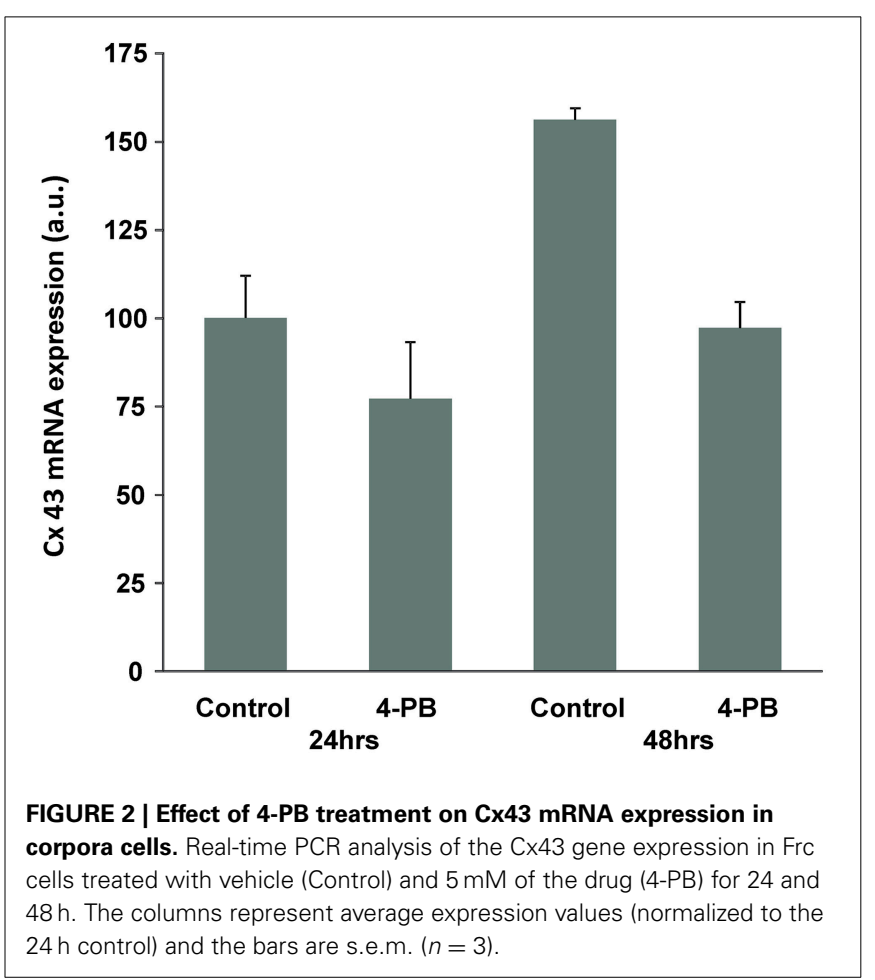




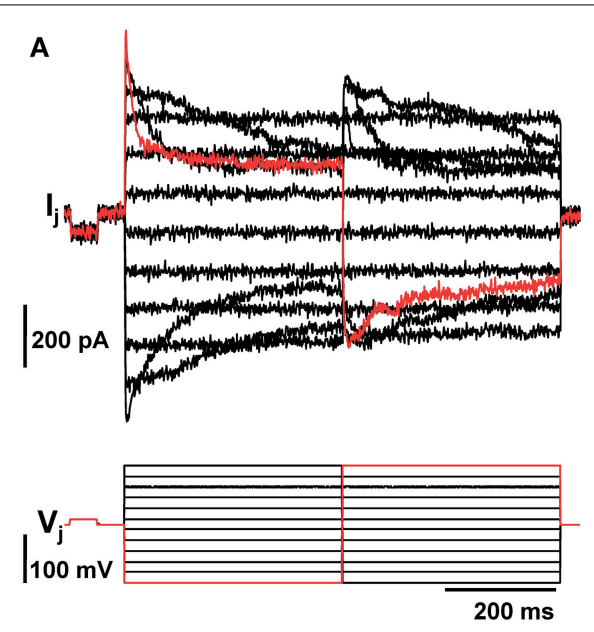

FIGURE 3 | Dual whole cell patch clamp of corpora cell pair. (A) Junctional currents recorded in one cell of a pair generated in response to voltage steps in the other. Upper records are junctional current, lower record shows the voltage steps. (B) Steady state junctional conductance $\left(\mathrm{G}_{\mathrm{SS}} / \mathrm{G}_{\mathrm{Ins}} t\right)$ plotted against transjunctional voltage step as previously described (Wang et al.,

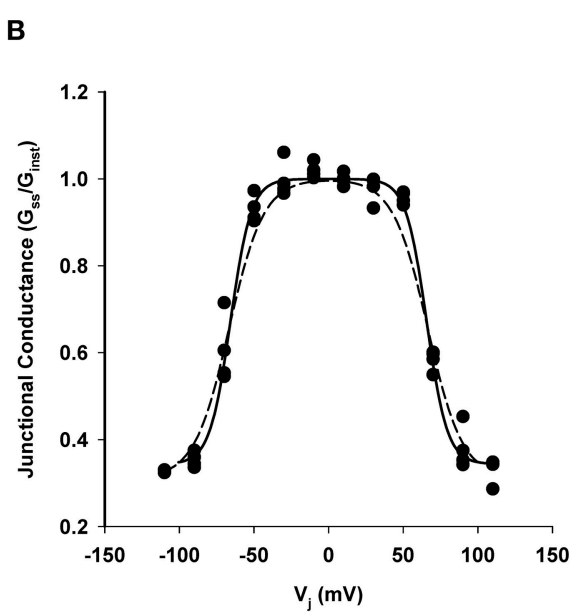

2010). Filled circles are the data shown in $\mathbf{A}$. All data points are from four different cell pairs exposed $4 \mathrm{~PB}(5 \mathrm{mM})$ for $24 \mathrm{~h}(n=4)$. Boltzmans fit of the 4 PB data set yielded a $V_{0}$ of $67 \mathrm{mV}$, a $g_{\min }$ of 0.33 . The dashed line represents a Boltzmans fit of control data with the following parameters: $V_{\mathrm{o}}=67 \mathrm{mV}$ and $g_{\min }=0.31$.

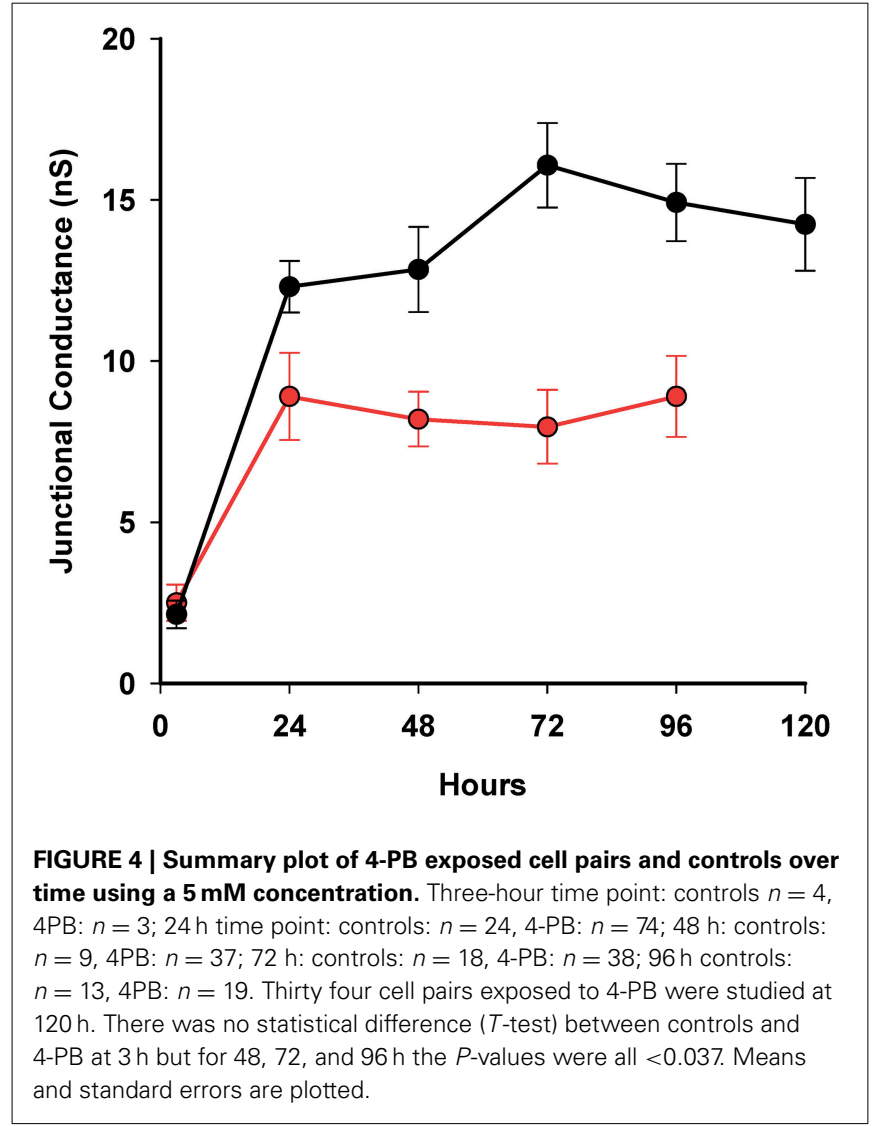

the $24 \mathrm{~h}$ controls $(p<0.01)$. Cx43 mRNA expression in the other three cell groups was not significantly different to each other.

The increase in Cx43 mRNA expression with time in culture was prevented by $4-\mathrm{PB}$ treatment, resulting in unchanged
Cx43 mRNA levels compared to the 24-h expression level and significantly lower expression relative to the 48-h control cells. Figures 1, 2 taken together suggest that 4-PB, stabilizes Cx43 through an as yet unidentified post-transcriptional mechanism.

4-PB did not affect the voltage dependence of junctional conductance nor was any change in steady state $G_{j}$ vs. $V_{j}$ observed relative to untreated corpora cell pairs (Rehman et al., 1997; Wang et al., 2001). To demonstrate voltage dependence cell pairs with junctional conductance of $10 \mathrm{nS}$ or less were chosen to minimize error due to series resistance. Figure 3A illustrates an example of junctional current $\left(\mathrm{I}_{\mathrm{j}}\right)$ generated in response to transjunctional voltage steps from a cell pair exposed for $48 \mathrm{~h}$ to $5 \mathrm{mM}$ of 4 - $\mathrm{PB}$. Voltage dependent behavior was identical for $4 \mathrm{~PB}$ and controls. Figure $3 \mathbf{B}$ shows the steady state normalized $G_{j}-V_{j}$ relationship for the data shown in Figure 3A and control data as well.

To assess whether $4 \mathrm{~PB}$ resulted in an increase in junctional conductance it was necessary to generate a database where average junctional conductance was determined at various time points during exposure to 4-PB. The data shown in Figure 4 illustrates that exposure to 4 -PB resulted in increased junctional conductance relative to controls. The time course with and without 4-PB over a 5 days period is illustrated. In all cases cells were plated out and then exposed to $5 \mathrm{mM} 4$ - $\mathrm{PB}$ or received an equivalent value of media (control) and at various times points dual whole cell patch clamp was performed to assess the magnitude of junctional conductance. The time course to reach an apparent steady state is approximately the same but the extent of coupling is $\sim 2 \times$ greater with 4-PB exposure. In transfected HeLa cells and HEK cells $4 \mathrm{~PB}$ increased junctional conductance $\sim 1.44$ over controls (Kaufman et al., 2013). The data are consistent with a stabilization of $\mathrm{Cx} 43$ channels such that the degradation rate is slowed relative to the insertion rate. An alternative explanation is an increase in the number of functional channels arising out of a pool of intact but normally silent channels. 


\section{DISCUSSION}

These data demonstrate 4-PB exposure results in enhanced junctional conductance $(\sim 2 \mathrm{X})$ consistent with previous observations on other cell types (Asklund et al., 2004; Khan et al., 2007; Kaufman et al., 2013). It is also clear from the gene expression data that post-transcriptional mechanisms dominate in determining the final level of functional $\mathrm{Cx} 43$ protein expression since mRNA levels are significantly reduced (Figure 2 ). Up-regulation of $\mathrm{Cx} 43$ protein expression and function has been documented in several cell types, by our group and others (Ammerpohl et al., 2004; Asklund et al., 2004; Hattori et al., 2007; Khan et al., 2007; Kaufman et al., 2013). In marked contrast here we find no change in apparent protein expression while Cx43 mRNA expression is decreased following 48-h treatment with 4 -PB, as has also been observed by Hattori et al. (2007).

It has been suggested that HDAC inhibitors might increase Cx43 translation or stabilize the existing pool of proteins (Hattori et al., 2007) and our data are consistent with this hypothesis, suggesting that functional $\mathrm{Cx} 43$ channels are the end result of broad effects of HDAC inhibition on the network of genes controlling $\mathrm{Cx} 43$ translation and post-translational expression.

The apparent down-regulation of $\mathrm{Cx} 43 \mathrm{mRNA}$ at $48 \mathrm{~h}$ in culture may also reflect network effects of the drug or could be an example of a weak negative feedback control, by which an increase in $\mathrm{Cx} 43$ protein leads to a modest decrease in mRNA transcription.

Another possibility to explain the enhanced junctional conductance is an increased channel open time for a population of channels but this is a less likely explanation based on previous studies using corpora smooth muscle cell pairs where open probability of $\mathrm{Cx} 43$ was shown to approach unity (Brink et al., 1996; Christ and Brink, 1999; Wang et al., 2001) even with substantial applied transjunctional potentials. It is also possible that increased junctional conductance is the result of recruitment or activation of intact but silent channels to a functional state (Bukauskas et al., 2000). How 4-PB might trigger such an occurrence is not clear.

The lack of effect on voltage dependence and the steady state $G_{j}-V_{j}$ relationship also suggests that expression of other connexins was not significant. The $G_{j}-V_{j}$ plot shown in Figure 3 is the same as records previously published for rat corpora cell pairs (Wang et al., 2001) suggesting that the profile of connexin expression was not altered by 4-PB. It is possible that the expression of other connexins is occurring with exposure to 4-PB but the percentage of functional channels other than Cx43 must be small. If there were significant expression of other connexin types the resultant $G_{j}-V_{j}$ plot would be different due to the presence of other homotypic channels and/or heterotypic channels (Brink et al., 1997, 2000) We were unable to monitor single channel conductance from cell pairs that were exposed for $24 \mathrm{~h}$ or more because the macroscopic junctional conductance was elevated to junctional conductances above $10 \mathrm{nS}$ where it is impossible to directly observe single channel activity. But in a recent study (Kaufman et al., 2013) Cx43 unitary conductance was shown to be unaffected by 4-PB exposure. The data also suggested that there was little or no change in open time probability for $\mathrm{Cx} 43$ gap junction channels.
Aging, diabetes, and hypertension all result in reduced expression of $\mathrm{Cx} 43$ in animal models and in human males and all three are associated with a higher incidence of erectile dysfunction (Pointis, 2006). Present approaches to alleviate erectile dysfunction center on the therapeutic inhibition of phosphodiesterase $\mathrm{V}$ (PDE5) resulting in elevated cGMP concentrations that then trigger relaxation by reducing cytoplasmic calcium levels. $4 \mathrm{~PB}$ and other related derivatives (Shieh et al., 2012) represent an alternative potential therapy for erectile dysfunction that acts to enhance protein expression by inhibition of HDAC. The use of HDAC inhibitors as a treatment for other conditions such as diabetes and hypertension is also possible if $\mathrm{Cx} 43$ expression or other relevant proteins in those diseases can be shown to reduce symptoms (Shieh et al., 2012).

\section{ACKNOWLEDGMENTS}

This work was supported by NIH grants RO-1 GM088180 to Peter R. Brink and RO-1 GM088181 to Virginijus Valiunas. The work of Barbara Rosati and David McKinnon was supported by VA Merit Review Award and by the Molecular Cardiology Institute at Stony Brook University. The authors wish to thank Josh Kaufman and Oliva Swanson for their assistance in the performance of this research project.

\section{REFERENCES}

Ammerpohl, O., Thormeyer, D., Khan, Z., Appelskog, I. B., Gojkovic, Z., Almqvist, P. M., et al. (2004). HDACi phenylbutyrate increases bystander killing of HSVtk transfected glioma cells. Biochem. Biophys. Res. Commun. 324, 8-14. doi: 10.1016/j.bbrc.2004.09.016

Asklund, T., Appelskog, I. B., Ammerpohl, O., Ekstrom, T. J., and Almqvist, P. M. (2004). Histone deacetylase inhibitor 4-phenylbutyrate modulates glial fibrillary acidic protein and connexin 43 expression, and enhances gap-junction communication, in human glioblastoma cells. Eur. J. Cancer 40, 1073-1081. doi: 10.1016/j.ejca.2003.11.034

Axelsen, L. N., Stahlhut, M., Mohammed, S., Larsen, B. D., Nielsen, M. S., Holstein-Rathlou, N. H., et al. (2006). Identification of ischemia-regulated phosphorylation sites in connexin43: a possible target for the antiarrhythmic peptide analogue rotigaptide (ZP123). J. Mol. Cell. Cardiol. 40, 790-798. doi: 10.1016/j.yjmcc.2006.03.005

Brink, P. R., Cronin, K., Banach, K., Peterson, E., Westphale, E. M., Seul, K. H., et al. (1997). Evidence for heteromeric gap junction channels formed from rat connexin43 and human connexin37. Am. J. Physiol. 273(4 Pt 1), C1386-C1396.

Brink, P. R., Ramanan, S. V., and Christ, G. J. (1996). Human connexin 43 gap junction channel gating: evidence for mode shifts and/or heterogeneity. Am. J. Physiol. 271(1 Pt 1), C321-C331.

Brink, P. R., Ricotta, J., and Christ, G. J. (2000). Biophysical characteristics of gap junctions in vascular wall cells: implications for vascular biology and disease. Braz. J. Med. Biol. Res. 33, 415-422. doi: 10.1590/S0100-879X20000004 00007

Bukauskas, F. F., Jordan, K., Bukauskiene, A., Bennett, M. V., Lampe, P. D., Laird, D. W., et al. (2000). Clustering of connexin 43-enhanced green fluorescent protein gap junction channels and functional coupling in living cells. Proc. Natl. Acad. Sci. U.S.A. 97, 2556-2561. doi: 10.1073/pnas.050588497

Christ, G. J., and Brink, P. R. (1999). Analysis of the presence and physiological relevance of subconducting states of Connexin43-derived gap junction channels in cultured human corporal vascular smooth muscle cells. Circ. Res. 84, 797-803. doi: 10.1161/01.RES.84.7.797

Christ, G. J., and Lue, T. (2004). Physiology and biochemistry of erections. Endocrine 23, 93-100. doi: 10.1385/ENDO:23:2-3:093

Eloff, B. C., Gilat, E., Wan, X., and Rosenbaum, D. S. (2003). Pharmacological modulation of cardiac gap junctions to enhance cardiac conduction: evidence supporting a novel target for antiarrhythmic therapy. Circulation 108, 3157-3163. doi: 10.1161/01.CIR.0000101926.43759.10 
Ferreira-Cornwell, M. C., Luo, Y., Narula, N., Lenox, J. M., Lieberman, M., and Radice, G. L. (2002). Remodeling the intercalated disc leads to cardiomyopathy in mice misexpressing cadherins in the heart. J. Cell Sci. 115(Pt 8), 1623-1634.

Fu, Q., Lv, J. J., and Zhang, H. (2008). Effects of chronic renal failure on the expression of connexin 43 in the rat's corpus cavernosum. Asian J. Androl. 10, 286-289. doi: 10.1111/j.1745-7262.2008.00334.x

Harris, A. L. (2001). Emerging issues of connexin channels: biophysics fills the gap. Q. Rev. Biophys. 34, 325-472. doi: 10.1017/S0033583501003705

Hattori, Y., Fukushima, M., and Maitani, Y. (2007). Non-viral delivery of the connexin 43 gene with histone deacetylase inhibitor to human nasopharyngeal tumor cells enhances gene expression and inhibits in vivo tumor growth. Int. J. Oncol. 30,1427-1439. doi: 10.3892/ijo.30.6.1427

Iwasaki, H., Watanabe, H., Iida, M., Ogawa, S., Tabe, M., Higaki, K., et al. (2006). Fibroblast screening for chaperone therapy in beta-galactosidosis. Brain Dev. 28 , 482-486. doi: 10.1016/j.braindev.2006.02.002

Jongen, W. M., Fitzgerald, D. J., Asamoto, M., Piccoli, C., Slaga, T. J., Gros, D., et al. (1991). Regulation of connexin 43-mediated gap junctional intercellular communication by $\mathrm{Ca} 2+$ in mouse epidermal cells is controlled by E-cadherin. J. Cell Biol. 114, 545-555. doi: 10.1083/jcb.114.3.545

Kaufman, J., Gordon, C., Bergamaschi, R., Wang, H. Z., Cohen, I. S., Valiunas, V., et al. (2013). The effects of the histone deacetylase inhibitor 4-phenylbutyrate on gap junction conductance and permeability. Front. Pharmacol. 4:111. doi: 10.3389/fphar.2013.00111

Khan, Z., Akhtar, M., Asklund, T., Juliusson, B., Almqvist, P. M., and Ekstrom, T. J. (2007). HDAC inhibition amplifies gap junction communication in neural progenitors: potential for cell-mediated enzyme prodrug therapy. Exp. Cell Res. 313, 2958-2967. doi: 10.1016/j.yexcr.2007.05.004

Li, J., Patel, V. V., and Radice, G. L. (2006). Dysregulation of cell adhesion proteins and cardiac arrhythmogenesis. Clin. Med. Res. 4, 42-52. doi: 10.3121/cmr.4.1.42

Melman, A., and Christ, G. J. (2001). Integrative erectile biology. The effects of age and disease on gap junctions and ion channels and their potential value to the treatment of erectile dysfunction. Urol. Clin. North. Am. 28, 217-231, vii. doi: 10.1016/S0094-0143(05)70133-6

Perlmutter, D. H. (2002). Chemical chaperones: a pharmacological strategy for disorders of protein folding and trafficking. Pediatr. Res. 52, 832-836. doi: 10.1203/00006450-200212000-00004

Pointis, G. (2006). Connexin43: emerging role in erectile function. Int. J. Biochem. Cell Biol. 38, 1642-1646. doi: 10.1016/j.biocel.2006.03.007

Prowse, D. M., Cadwallader, G. P., and Pitts, J. D. (1997). E-cadherin expression can alter the specificity of gap junction formation. Cell Biol. Int. 21, 833-843. doi: 10.1006/cbir.1997.0202

Rehman, J., Chenven, E., Brink, P., Peterson, B., Walcott, B., Wen, Y. P., et al. (1997). Diminished neurogenic but not pharmacological erections in the 2- to 3-month experimentally diabetic F-344 rat. Am. J. Physiol. 272(4 Pt 2), H1960-H1971.

Rosati, B., Yan, Q., Lee, M. S., Liou, S. R., Ingalls, B., Foell, J., et al. (2011). Robust L-type calcium current expression following heterozygous knockout of the Cav1.2 gene in adult mouse heart. J. Physiol. 589(Pt 13), 3275-3288. doi: 10.1113/jphysiol.2011.210237

Ruijter, J. M., Pfaffl, M. W., Zhao, S., Spiess, A. N., Boggy, G., Blom, J., et al. (2013). Evaluation of qPCR curve analysis methods for reliable biomarker discovery: bias, resolution, precision, and implications. Methods 59, 32-46. doi: 10.1016/j.ymeth.2012.08.011

Shieh, J. M., Wei, T. T., Tang, Y. A., Huang, S. M., Wen, W. L., Chen, M. Y., et al. (2012). Mitochondrial apoptosis and FAK signaling disruption by a novel histone deacetylase inhibitor, HTPB, in antitumor and antimetastatic mouse models. PLoS ONE 7:e30240. doi: 10.1371/journal.pone.0030240
Singh, O. V., Vij, N., Mogayzel, P. J. Jr., Jozwik, C., Pollard, H. B., and Zeitlin, P. L. (2006). Pharmacoproteomics of 4-phenylbutyrate-treated IB3-1 cystic fibrosis bronchial epithelial cells. J. Proteome Res. 5, 562-571. doi: 10.1021/pr050319o

Suadicani, S. O., Urban-Maldonado, M., Tar, M. T., Melman, A., and Spray, D. C. (2009). Effects of ageing and streptozotocin-induced diabetes on connexin43 and P2 purinoceptor expression in the rat corpora cavernosa and urinary bladder. BJU Int. 103, 1686-1693. doi: 10.1111/j.1464-410X.2008.08337.x

Tang, X. X., Robinson, M. E., Riceberg, J. S., Kim, D. Y., Kung, B., Titus, T. B., et al. (2004). Favorable neuroblastoma genes and molecular therapeutics of neuroblastoma. Clin. Cancer Res. 10, 5837-5844. doi: 10.1158/1078-0432.CCR-04-0395

Valiunas, V., Beyer, E. C., and Brink, P. R. (2002). Cardiac gap junction channels show quantitative differences in selectivity. Circ. Res. 91, 104-111. doi: 10.1161/01.RES.0000025638.24255.AA

Valiunas, V., Gemel, J., Brink, P. R., and Beyer, E. C. (2001). Gap junction channels formed by coexpressed connexin40 and connexin43. Am. J. Physiol. Heart Circ. Physiol. 281, H1675-H1689.

VanSlyke, J. K., and Musil, L. S. (2005). Cytosolic stress reduces degradation of connexin43 internalized from the cell surface and enhances gap junction formation and function. Mol. Biol. Cell 16, 5247-5257. doi: 10.1091/mbc.E05-05-0415

Wang, H. Z., Day, N., Valcic, M., Hsieh, K., Serels, S., Brink, P. R., et al. (2001). Intercellular communication in cultured human vascular smooth muscle cells. Am. J. Physiol. Cell Physiol. 281, C75-C88.

Wang, W., Gao, J., Entcheva, E., Cohen, I. S., Gordon, C., and Mathias, R. T. (2010). A transmural gradient in the cardiac $\mathrm{Na} / \mathrm{K}$ pump generates a transmural gradient in Na/Ca exchange. J. Membr. Biol. 233, 51-62. doi: 10.1007/s00232010-9224-y

Wei, C. J., Francis, R., Xu, X., and Lo, C. W. (2005). Connexin43 associated with an $\mathrm{N}$-cadherin-containing multiprotein complex is required for gap junction formation in NIH3T3 cells. J. Biol. Chem. 280, 19925-19936. doi: 10.1074/jbc.M412921200

Wirth, B., Brichta, L., and Hahnen, E. (2006). Spinal muscular atrophy: from gene to therapy. Semin. Pediatr. Neurol. 13, 121-131. doi: 10.1016/j.spen.2006.06.008

Xing, D., Kjolbye, A. L., Nielsen, M. S., Petersen, J. S., Harlow, K. W., HolsteinRathlou, N. H., et al. (2003). ZP123 increases gap junctional conductance and prevents reentrant ventricular tachycardia during myocardial ischemia in open chest dogs. J. Cardiovasc. Electrophysiol. 14, 510-520. doi: 10.1046/j.15408167.2003.02329.x

Conflict of Interest Statement: The authors declare that the research was conducted in the absence of any commercial or financial relationships that could be construed as a potential conflict of interest.

Received: 17 March 2014; accepted: 11 January 2015; published online: 03 February 2015.

Citation: Wang HZ, Rosati B, Gordon C, Valiunas V, McKinnon D, Cohen IS and Brink PR (2015) Inhibition of histone deacetylase (HDAC) by 4-phenylbutyrate results in increased junctional conductance between rat corpora smooth muscle cells. Front. Pharmacol. 6:9. doi: 10.3389/fphar.2015.00009

This article was submitted to Integrative and Regenerative Pharmacology, a section of the journal Frontiers in Pharmacology.

Copyright (c) 2015 Wang, Rosati, Gordon, Valiunas, McKinnon, Cohen and Brink. This is an open-access article distributed under the terms of the Creative Commons Attribution License (CC BY). The use, distribution or reproduction in other forums is permitted, provided the original author(s) or licensor are credited and that the original publication in this journal is cited, in accordance with accepted academic practice. No use, distribution or reproduction is permitted which does not comply with these terms. 